\title{
Influence of bFGF on in vitro expansion and chondrogenic construction of articular cartilage-derived progenitor cells
}

\author{
Xu Shen ${ }^{1,2 \#}$, Tianfeng Zhu ${ }^{1 \#}$, Jixin Xue ${ }^{3 \#}$, Yijian Zhang ${ }^{1}$, Yingjie Lu ${ }^{1}$, Huilin Yang ${ }^{1}$, Zhengyuan Yu ${ }^{4}$, \\ Yueqian $\mathrm{Zhu}^{5}$, Xuesong $\mathrm{Zhu}^{1}$ \\ ${ }^{1}$ Department of Orthopedics, the First Affiliated Hospital of Soochow University, Suzhou, China; ${ }^{2}$ Department of Orthopedics, Suzhou Dushu Lake \\ Hospital, Dushu Lake Hospital Affiliated to Soochow University, Suzhou, China; ${ }^{3}$ Department of Orthopedics, The Second Affiliated Hospital and \\ Yuying Children's Hospital of Wenzhou Medical University, Wenzhou, China; ${ }^{4}$ Department of Oncology, the First Affiliated Hospital of Soochow \\ University, Suzhou, China; ${ }^{5}$ Department of Dermatology, the First Affiliated Hospital of Soochow University, Suzhou, China \\ Contributions: (I) Conception and design: X Zhu, Y Zhu, Z Yu; (II) Administrative support: H Yang, X Zhu; (III) Provision of study materials or \\ patients: X Shen, Y Zhu; (IV) Collection and assembly of data: X Shen, T Zhu; J Xue; (V) Data analysis and interpretation: X Shen, Y Zhu, X Zhu; (VI) \\ Manuscript writing: All authors; (VII) Final approval of manuscript: All authors. \\ \#These authors contributed equally to this work. \\ Correspondence to: Xuesong Zhu. Department of Orthopedics, the First Affiliated Hospital of Soochow University, Suzhou, China. \\ Email: zhuxs@126.com; Yueqian Zhu. Department of Dermatology, the First Affiliated Hospital of Soochow University, Suzhou, China. \\ Email: zhuyueqian0711@126.com; Zhengyuan Yu. Department of Oncology, the First Affiliated Hospital of Soochow University, Suzhou, China. \\ Email: strongeryy1985@163.com.
}

Background: Articular cartilage-derived progenitor cells (ACPCs) possess the properties of both chondrocytes and bone marrow mesenchymal stem cells (BMSCs). However, the number of ACPCs in articular cartilage is low, and an effective culture system is needed for their expansion. Basic fibroblast growth factor (bFGF) promotes the expansion of chondrocytes and BMSCs, as well as the chondrogenic differentiation of BMSCs. Therefore, the aim of this study was to clarify whether bFGF could be used for in vitro expansion of ACPCs and whether bFGF promoted chondrogenic construction of ACPCs.

Methods: We applied the fibronectin adhesion method to sort mice ACPCs and compared the proliferative, osteogenic, and chondrogenic abilities of ACPCs by adding various concentration of bFGF ( 0,2 , and $5 \mathrm{ng} / \mathrm{mL}$ ) to the cell culture medium. Then used the best system to construct cartilage with ACPCs in vitro and in vivo.

Results: The results indicated that bFGF promoted ACPCs proliferation, inhibited osteogenesis, and promoted chondrogenesis, and that a cell culture system containing $2 \mathrm{ng} / \mathrm{mL} \mathrm{bFGF}$ was optimal for these effects. ACPCs constructed cartilage using the filtered culture system presented homogeneous cartilaginous histological structure in vitro and in vivo.

Conclusions: By applying this cell culture system, homogenous cartilage tissue was constructed in vitro and in vivo by chondrogenic induction, which provides a stable cell expansion culture method for the application of ACPCs in cartilage repair.

Keywords: Articular cartilage-derived progenitor cells (ACPCs); basic fibroblast growth factor (bFGF); cell expansion; cartilage construction

Submitted Apr 06, 2021. Accepted for publication Jan 05, 2022.

doi: $10.21037 / \mathrm{atm}-21-5604$

View this article at: https://dx.doi.org/10.21037/atm-21-5604 


\section{Introduction}

Autologous repair of cartilage defects is difficult. Cell therapy is developing rapidly, and mesenchymal stem cells, such as bone marrow mesenchymal stem cells (BMSCs), are widely used to treat cartilage defects (1-4). However, BMSCs take a long time to be induced into cartilage in vitro and regenerated cartilage is unstable in the in vivo environment, easily becoming vascularized and fibrotic (5-8).

Articular cartilage-derived progenitor cells (ACPCs) are derived from articular cartilage accounting for approximately $0.1 \%$ of chondrocytes and are mainly located in the superficial layer of cartilage, with a small number in the deep layer (9-11). ACPCs possess both chondrocyte and BMSC properties, in that they express cartilagespecific matrix. Moreover, ACPCs have multi-directional differentiation ability and strong proliferation ability, making them excellent seed cells. Due to the lack of specific surface markers, fibronectin adhesion is currently used to isolate ACPCs. However, as chondrogenesis requires many functional seed cells, ACPCs need to be massively expanded, but there is no unified protocol for how to maintain the stem cell characteristics and chondrogenic ability of ACPCs during the expansion process. Basic fibroblast growth factor (bFGF) is a growth factor commonly used in the culture of chondrocytes and BMSCs for cartilage tissue engineering (12-15) and can promote the proliferation of chondrocytes and mesenchymal cells, as well as chondrogenic differentiation of BMSCs (16-20). However, there are no relevant reports on whether it can be used for the mass expansion of ACPCs.

The mouse is an ideal animal model for studying the changes and characteristics of cells, because its gene lineage has been perfected and it has a complete set of biochemical related indicators. In this study we used the fibronectin adhesion method to isolate and extract ACPCs to evaluate their differentiation and proliferation abilities, and cell surface markers were identified to prove that the extracted cells were ACPCs. Medium containing different bFGF concentrations was then used to culture ACPCs, and the effect of bFGF on the proliferation ability, osteogenesis and chondrogenesis of ACPCs was evaluated to select the optimal concentration of bFGF. Finally, the optimal concentration of bFGF was used to culture ACPCs and to construct cartilage tissues in vitro and in vivo to evaluate its practical application value.

We present the following article in accordance with the ARRIVE reporting checklist (available at https://atm. amegroups.com/article/view/10.21037/atm-21-5604/rc).

\section{Methods}

Animals

Ninety specific pathogen free (SPF) C57BL/6 mice $(3.5 \pm 0.3 \mathrm{~g}$, male, 5 days old $)$ and fifteen nude mice $(15 \pm 0.5 \mathrm{~g}$, female, 4 weeks old, SPF grade) were purchased from the Shaoyan Medical Research Center of Soochow [SCXK(Su)2018-0006, SPF] and Animal Care and Experiment Committee of Soochow University. Before the implantation mice were housed in individually ventilated cages for 1 week. The cages were in a barrier system under conditions of $22-25^{\circ} \mathrm{C}, 50-60 \%$ humidity, a 12-hour light-dark cycle, and a cage air exchange of over 50 per hour. Animals were supplied with a certified rodent diet and sterilized municipal tap water in water bottles. A protocol was prepared before the study without registration. All animal experimental procedures were approved by the Animal Care and Experiment Committee of Soochow University (application numbers 201811A525, 201810A271), in compliance with institutional guidelines for the care and use of animals.

\section{Experimental design}

\section{Experimental materials}

Trypsin solution $(0.25 \%)$, fetal bovine serum (FBS), and penicillin manufactured by Thermo Fisher Scientific (Waltham, MA, USA) were used. The Type IV collagenase used was from Serva Electrophoresis GmbH (Heidelberg, Germany). DMEM/F12 (1:1) medium and high glucose DMEM were from Hyclone (Logan, UT, USA), and $\alpha-M E M$ complete medium was from Thermo Fisher Scientific. Fibronectin, L-ascorbic acid-2-phosphate, dexamethasone, and $\beta$-phosphoglycerol were all obtained from SigmaAldrich (St Louis, MO, USA). TGF- $\beta 1$, IGF-1, bFGF from R\&D Systems (Minneapolis, MN, USA). CD29-PE, CD31APC, CD44-APC, CD45-APC, CD73-PE, CD90-PE, CD105-PE, and Notch-1-PE from Biolegend (San Diego, CA, USA). The C57BL/6 mouse adipose mesenchymal stem cell lipogenesis induction medium was from Cyagen Biosciences (Guangzhou, China). Trypan Blue was from Beyotime (Shanghai, China). Alizarin Red Staining Kit from TIANDZ (Beijing, China). Oil Red O from Sigma-Aldrich. Crystal Violet from Beyotime. CCK-8 from Dojindo (Shanghai, China). Rabbit Anti-Mouse Type II Collagen, 
Type X Collagen, VEGF-A Monoclonal Antibody from Abcam (Cambridge, MA, USA). Trizol from Invitrogen (Carlsbad, CA, USA). DEPC Water from Thermo Fisher Scientific, and iTap ${ }^{\mathrm{TM}}$ Universal SYBR $^{\circledR}$ Green Supermix kit from Bio-Rad (Hercules, CA, USA).

\section{Isolation and cell culture of ACPCs}

The mixed knee and hip cartilage of ten C57BL/6 mice were harvested under aseptic conditions on an ultraclean bench. Following three rinses in phosphate-buffered saline (PBS), the isolated tissue was digested with $0.25 \%$ trypsin for $10 \mathrm{~min}$, then neutralized with DMEM/F12 (1:1) complete medium (containing 10\% FBS and 1\% penicillin). The sample was then rinsed three times with PBS, then $0.2 \%$ type IV collagenase was added, and the tissue was digested with shaking at $37{ }^{\circ} \mathrm{C}$ for $6-8 \mathrm{~h}$. The collagenasedigested tissue mixture was neutralized with DMEM/F12 (1:1) complete medium, a single cell suspension was then obtained by filtration through a $40 \mu \mathrm{m}$ single-cell filter, and the supernatant was discarded after centrifugation at $1,500 \mathrm{rpm}$ for $5 \mathrm{~min}$ at $25^{\circ} \mathrm{C}$. The isolated cells were counted by the Trypan blue method $(9 \mu \mathrm{L}$ cell suspension mixed with $1 \mu \mathrm{L}$ Trypan blue) using a cell counting plate, and further plated onto a fibronectin-coated plate at a density of $1 \times 10^{6}$ cells/plate (diameter of $10 \mathrm{~cm}$ ) and incubated at $37{ }^{\circ} \mathrm{C}$ with $5 \% \mathrm{CO}_{2}$ for $18 \mathrm{~min}$. The top layer of liquid was aspirated off, cells were rinsed once with DMEM/F12 (1:1) complete medium, and then cultured in $10 \mathrm{~mL}$ DMEM/F12 (1:1) complete medium per plate. When the P0 generation ACPCs reached $80 \%$ confluence, the medium was aspirated, the cells were rinsed in PBS and $2 \mathrm{~mL} 0.25 \%$ trypsin was added for digestion. After incubation for $2 \mathrm{~min}$, an equal volume of DMEM/F12 (1:1) was added to terminate the reaction, and the resuspended cells were then used for subsequent experiments.

\section{Flow cytometric analysis}

The cell suspension was centrifuged at 1,500 rpm for $5 \mathrm{~min}$ at $25^{\circ} \mathrm{C}$, the supernatant was discarded, and the ACPCs were resuspended in PBS containing 1\% FBS, then filtered into single cell suspensions. After counting the cells, the cell suspensions were adjusted to $1 \times 10^{6}$ cells $/ \mathrm{mL}$ and $1 \mu \mathrm{L}$ of CD29-PE, CD31-APC, CD44-APC, CD45-APC, CD73PE, CD90-PE, CD105-PE, or Notch-1-PE was added, as appropriate. Antibody-free liquid was used as blank control. Cells were incubated at $4{ }^{\circ} \mathrm{C}$ for 30 min with shaking 5 times every $5 \mathrm{~min}$, and the suspensions were then centrifuged at $1,800 \mathrm{rpm}$ for $5 \mathrm{~min}$ at $4^{\circ} \mathrm{C}$ and rinsed twice with PBS.
Finally, PBS containing 1\% FBS was used to resuspend the mixture, and the fluorescent expression of surface markers was detected by flow cytometry.

\section{Chondrogenic induction}

The cell suspension was centrifuged at 1,500 rpm for $5 \mathrm{~min}$ at $25^{\circ} \mathrm{C}$, then the upper liquid was discarded, and the cells were resuspended by adding DMEM/F12 (1:1) complete medium. Next, $9 \mu \mathrm{L}$ of cell suspension was aspirated and mixed with $1 \mu \mathrm{L}$ of Trypan Blue, and cells were counted on a cell counting plate. A total of $0.5 \times 10^{6}$ cells per tube were transferred to a $15-\mathrm{mL}$ centrifuge tube, medium was added to $2 \mathrm{~mL}$, and the suspension was centrifuged at $1,080 \mathrm{rpm}$ for $5 \mathrm{~min}$, then the collected cells were left for 3 days to form cell pellets. After this, the medium in the chondrogenic induction group was replaced with chondrogenic induction medium (high glucose DMEM containing $1 \%$ penicillin, $10 \mathrm{ng} / \mathrm{mL}$ TGF- $\beta 1,50 \mathrm{ng} / \mathrm{mL}$ IGF-1, and $40 \mathrm{ng} / \mathrm{mL}$ dexamethasone), while the nonchondrogenic induction groups received high glucose DMEM complete medium (containing 10\% FBS and 1\% penicillin) every 3 days. After 21 days, cell pellets were paraffin embedded and then stained.

\section{Osteogenic induction}

The cell suspension was centrifuged at 1,500 rpm for $5 \mathrm{~min}$ at $25{ }^{\circ} \mathrm{C}$, the supernatant was discarded, and cells were resuspended in DMEM/F12 (1:1) complete medium. Next, $9 \mu \mathrm{L}$ cell suspension was mixed with $1 \mu \mathrm{L}$ Trypan blue and the cells were counted on a cell counting plate. Culture plates were seeded with $5 \times 10^{4}$ cells per well (diameter of $10 \mathrm{~cm}$ ) and incubated at $37{ }^{\circ} \mathrm{C}$ in an atmosphere of $5 \% \mathrm{CO}_{2}$. After the cells reached $80 \%$ confluence, the medium in the induction group was replaced with osteogenic induction medium (high glucose DMEM complete medium containing $10 \mu \mathrm{g} / \mathrm{mL}$ L-ascorbic acid-2-phosphate, $2.16 \mathrm{~g} / \mathrm{L} \beta$-phosphoglycerol, and $40 \mathrm{ng} / \mathrm{mL}$ dexamethasone), while the non-induction group received high glucose DMEM complete medium. The medium was changed every 3 days, cell status and growth were observed under an inverted microscope. Alizarin red S staining was performed after 21 days. The Alizarin red S staining procedure was as follows. The culture medium was aspirated and a $2 \mathrm{~mL} /$ well of PBS was added for two rinses. The cell layer was then fixed in a $2 \mathrm{~mL} /$ well of anhydrous ethanol for $30 \mathrm{~min}$, then rinsed twice with a $1 \mathrm{~mL} /$ well of distilled water. To stain, a $1 \mathrm{~mL} /$ well of alizarin red S-staining solution was added and incubated for $20 \mathrm{~min}$, after which the staining solution was aspirated and the cells were rinsed four 
times with a $1 \mathrm{~mL} /$ well of distilled water.

\section{Adipogenic induction}

The cell suspension was centrifuged at 1,500 rpm for $5 \mathrm{~min}$ at $25^{\circ} \mathrm{C}$, the supernatant was discarded, and cells were resuspended in DMEM/F12 (1:1) complete medium. For cell counts, $9 \mu \mathrm{L}$ of cell suspension was mixed with $1 \mu \mathrm{L}$ of Trypan blue and cells were counted on a cell counting plate. Culture plates were then seeded with $5 \times 10^{4}$ cells per well (diameter of $3.5 \mathrm{~cm}$ ) and incubated at $37^{\circ} \mathrm{C}$ with $5 \% \mathrm{CO}_{2}$. After the cells grew to $70-80 \%$ confluence, the medium in the induction group was replaced with adipogenic medium (C57BL/6 mouse adipose MSC adipogenic medium), while in the non-induction group, it was replaced with high glucose DMEM complete medium. The medium was changed according to the instructions, cell status and growth were observed under an inverted microscope. After 21 days, the cells were stained with Oil Red O. The specific staining steps of the Oil Red O procedure were as follows. The medium was aspirated, wells were washed twice with a $2 \mathrm{~mL} /$ well of PBS, then fixed with a $2 \mathrm{~mL} /$ well of paraformaldehyde for $30 \mathrm{~min}$ and rinsed twice with a $1 \mathrm{~mL} /$ well of distilled water. Cells were stained with a $1 \mathrm{~mL} /$ well of Oil Red O staining solution for $30 \mathrm{~min}$, after which the staining solution was aspirated, and wells were rinsed three times with a $1 \mathrm{~mL} /$ well of distilled water.

\section{Effect of bFGF on the clone-forming ability of ACPCs}

When the P0 generation ACPCs reached 80\% confluence, the $\mathrm{P} 1$ generation of ACPCs were replated and induced by different concentrations of bFGF. After aspirating the medium, the cell layer was rinsed once with PBS, then $2 \mathrm{~mL}$ of $0.25 \%$ trypsin was added for digestion, incubated for $2 \mathrm{~min}$, and an equal amount of DMEM/F12 (1:1) complete medium was added to terminate the reaction. After centrifugation at $1,500 \mathrm{rpm}$ for $5 \mathrm{~min}$ at $25^{\circ} \mathrm{C}$, the supernatant was discarded and the cells were resuspended and equally distributed in $8 \mathrm{~mL} \alpha-M E M$ complete medium (containing $10 \% \mathrm{FBS}$ and $1 \%$ penicillin), without bFGF or with 2 or $5 \mathrm{ng} / \mathrm{mL}$ bFGF. Cells were counted by mixing $9 \mu \mathrm{L}$ of cell suspension with $1 \mu \mathrm{L}$ of Trypan Blue on a cell counting plate, then the plates were seeded with 5,000 cells/dish. After 2 weeks of incubation, crystal violet staining was performed, the morphology of cell colonies was observed under the microscope, and cell colonies with a diameter greater than $2 \mathrm{~mm}$ were counted. The crystal violet staining was performed as follows. The culture medium was aspirated, and dishes were rinsed once with a $3 \mathrm{~mL} /$ dish of PBS. Cells were then fixed with a $3 \mathrm{~mL} /$ dish of paraformaldehyde for $15 \mathrm{~min}$, after which they were washed twice with a $3 \mathrm{~mL} / \mathrm{dish}$ of distilled water. Next, a $3 \mathrm{~mL} /$ well of crystal violet staining solution was added and incubated for $30 \mathrm{~min}$, then rinsed again with $3 \mathrm{~mL} /$ well of distilled water.

\section{Effect of bFGF on the proliferative capacity of ACPCs}

Cultured ACPCs were prepared as described above, resuspended in $8 \mathrm{~mL} \alpha$-MEM complete medium, and 1,000 cells per well were seeded into 96 -well plates and cultured without or with bFGF at 2 or $5 \mathrm{ng} / \mathrm{mL}$ in $\alpha-M E M$. On days $1,2,3,5,7$, and 9 , fresh medium containing $10 \%$ CCK-8 reagent was added and cells were incubated at $37^{\circ} \mathrm{C}$ for $2 \mathrm{~h}$. The culture medium was then aspirated and the absorbance at $450 \mathrm{~nm}$ (OD450) was measured using a spectrophotometer.

\section{Effect of bFGF on the osteogenic capacity of ACPCs}

The medium was removed from the P1 ACPCs induced by different concentrations of bFGF, cells were rinsed once in PBS, then digested with $2 \mathrm{~mL}$ of $0.25 \%$ trypsin for $2 \mathrm{~min}$. An equal amount of DMEM/F12 (1:1) complete medium was then added to terminate the reaction. Cells were centrifuged at $1,500 \mathrm{rpm}$ for $5 \mathrm{~min}$ at $25^{\circ} \mathrm{C}$, the supernatant was discarded, and cells were resuspended and equally distributed in $\alpha$-MEM complete medium without or with bFGF at 2 or $5 \mathrm{ng} / \mathrm{mL}$. Cells were counted as described above, and $5 \times 10^{4}$ cells per well were seeded into wells of six-well plates and incubated at $37{ }^{\circ} \mathrm{C}$ with $5 \% \mathrm{CO}_{2}$. After the cells reached $70-80 \%$ confluence, the medium in the osteogenic induction group was replaced with osteogenic induction medium, while in the osteogenic non-induction group it was replaced with high glucose DMEM containing $10 \%$ FBS. After 21 days, alizarin red S staining and RTPCR were performed.

\section{Effect of bFGF on the chondrogenic capacity of ACPCs}

The medium was removed from the P1 ACPCs induced by different concentrations of bFGF, cells were rinsed once in PBS, then digested with $2 \mathrm{~mL}$ of $0.25 \%$ trypsin for $2 \mathrm{~min}$. An equal amount of DMEM/F12 (1:1) complete medium was then added to terminate the reaction. Cells were centrifuged at $1,500 \mathrm{rpm}$ for $5 \mathrm{~min}$ at $25^{\circ} \mathrm{C}$, the supernatant was discarded, and cells were resuspended and equally 
Table 1 Primer sequences

\begin{tabular}{lll}
\hline Gene & Forward primer (5'-3') & Reverse primer (5'-3') \\
\hline Aggrecan & TAGAGGATGTGAGTGGTCTT & TCCACTAAGGTACTGTCCAC \\
AKP & CCAACTCTITTGGGCCAGAGA & GGCTACATTGGTGTTGAGCTTTT \\
COL-II & CTGGTGGAGCAGCAAGAGCA & CAGTGGACAGTAGACGGAGGAAAG \\
COMP & TGGGCCCGCAGATGCTTC & AGGTTTTTGGTCTGATAGCTC \\
GAPDH & GGTGAAGGTCGGTGTGAACG & CTCGCTCCTGGAAGATGGTG \\
Osteocalcin & CTTGAAGACCGCCTACAAAC & GCTGCTGTGACATCCATAC \\
SOX9 & GCTTGACGTGGCTTGTC & GAGCCGGATCTGAAGAGGGA \\
\hline
\end{tabular}

AKP, alkaline phosphatase; COL-II, type II collagen; COMP, cartilage oligomeric matrix protein; SOX9, sex determining region Y-box 9.

distributed in $\alpha$-MEM complete medium without or with bFGF at 2 or $5 \mathrm{ng} / \mathrm{mL}$. Cells were counted and placed into a $15-\mathrm{mL}$ centrifuge tube at a density of $0.5 \times 10^{6}$ cells/tube, then $2 \mathrm{~mL}$ medium was added, the tubes were centrifuged at $1,080 \mathrm{rpm}$ for $5 \mathrm{~min}$, then left for 3 days for cell pellets to form. Chondrogenic induction medium was then added to the chondrogenic induction group, and high glucose DMEM complete medium was added to the chondrogenic non-induction group. The medium was changed every 3 days. After 21 days, hematoxylin and eosin (HE) staining, Type II collagen immunohistochemical staining and RTPCR were performed.

\section{RNA extraction}

The culture medium was aspirated, and cells were rinsed once with $2 \mathrm{~mL}$ PBS per well, then lysed with Trizol $(300 \mu \mathrm{L}$ per well of a 6-well plate) at room temperature for $5 \mathrm{~min}$. The lysate was transferred to an RNAase free EP tube for later use. Next, chloroform was added at a ratio of $5: 2$, mixed by vigorous shaking for $30 \mathrm{~s}$, allowed to stand on ice for $15 \mathrm{~min}$, then centrifuged at $4{ }^{\circ} \mathrm{C}, 12,000 \mathrm{rpm}$ for $15 \mathrm{~min}$. After centrifugation, $200-300 \mu \mathrm{L}$ of the intermediate transparent liquid was added to another RNAase-free EP tube, an equal amount of isopropanol was added, and the tube was mixed 10 times then allowed to stand on ice for $10 \mathrm{~min}$. After centrifuging at $4{ }^{\circ} \mathrm{C}$ and $12,000 \mathrm{rpm}$ for $15 \mathrm{~min}$, the supernatant was discarded, then a $1 \mathrm{~mL}$ per sample of $75 \%$ ethanol/DEPC water was added into the EP tube to resuspend the precipitate. After centrifuging at $4{ }^{\circ} \mathrm{C}$ and 7,500 rpm for $5 \mathrm{~min}$, the upper liquid was discarded and tubes air dried. Finally, $20 \mu \mathrm{L}$ of DEPC water was added to each tube and incubated at $58^{\circ} \mathrm{C}$ for $8 \mathrm{~min}$ in a metal block, then the RNA concentration was measured using a Nano
Drop 2000.

\section{Reverse transcription}

Reverse transcription was performed according to the instructions provided with the cDNA reverse transcription kit. The reaction system was prepared as follows. RNA $1 \mu \mathrm{g} ; 5 \times$ All-in-One RT MasterMix $2 \mu \mathrm{L}$, was made up to a $10-\mu \mathrm{L}$ reaction volume with DEPC water. The reverse transcription reaction was performed at $25^{\circ} \mathrm{C}$ for $10 \mathrm{~min}$, $42{ }^{\circ} \mathrm{C}$ for $15 \mathrm{~min}$, then $85^{\circ} \mathrm{C}$ for $5 \mathrm{~min}$, and samples were then placed on ice for subsequent operation.

\section{Real time PCR}

For each sample, a $1-\mu \mathrm{L}$ cDNA mixture, $0.5 \mu \mathrm{L}$ each of upstream and downstream primers, $8 \mu \mathrm{L} \mathrm{SYBR}^{\circledR}$ Green, and $12 \mu \mathrm{L}$ DEPC water were mixed and analyzed by RTPCR on a CFX96TM real-time PCR reaction machine. The PCR amplification conditions were pre-denaturation at $95{ }^{\circ} \mathrm{C}$ for $30 \mathrm{~s}$, denaturation at $95{ }^{\circ} \mathrm{C}$ for $5 \mathrm{~s}$, and extension at $60^{\circ} \mathrm{C}$ for $30 \mathrm{~s}, 40$ cycles. Quantitative analysis was performed by the fluorescence method and GAPDH was used as an internal reference gene. Primer sequences were as shown below (Table 1).

\section{In vitro and in vivo cartilage construction of ACPCs on materials}

The P2 generation of ACPCs cultured in $\alpha$-MEM with bFGF at $2 \mathrm{ng} / \mathrm{mL}$ were used in the following manner. The cell density was first adjusted to $10^{8}$ cells/mL, then the ACPCs-gelatin/polycaprolactone (Gt/PCL) complex was constructed. First, one layer of cells was seeded on the 
bottom of the well (diameter of $3.5 \mathrm{~cm}$ ), then one layer of material was covered, and another layer of cells was seeded. A total of six layers of cells were seeded on five layers of material and each layer of $4 \mu \mathrm{L}$ cells was seeded on the material. About $50 \mu \mathrm{L}$ of a $\alpha$-MEM medium with bFGF at $2 \mathrm{ng} / \mathrm{mL}$ was added to maintain the nutrition of the ACPCs-Geltin/PCL complexes at $30 \mathrm{~min}, 1 \mathrm{~h}, 2 \mathrm{~h}$, and $3 \mathrm{~h}$ respectively. Finally, a $1-\mathrm{mL} \alpha-M E M$ medium with bFGF at $2 \mathrm{ng} / \mathrm{mL}$ was added. Three days later, the medium was replaced with chondrogenic induction medium as previously detailed for 4 weeks. The complexes were then implanted subcutaneously in four nude mice three times, and the skin was sutured. An additional mouse was used to compensate for the death of an animal. After the operation, the nude mice were carefully fed, and sacrificed at the eighth week after implantation. All the implantation procedures and husbandry took place in the SPF animal house of Soochow University. The complexes were performed with HE staining and type II collagen/type X collagen/VEGF-A immunohistochemical staining.

\section{Statistical analysis}

Experimental data were expressed as mean \pm standard deviation, and statistical analysis was performed using SPSS19.0 software. $P$ values were calculated using the group $t$-test, and $\mathrm{P}$ values $<0.05$ were considered statistically significant.

\section{Results}

\section{Isolation and identification of ACPCs}

All C57BL/6 mice used for ACPCs extraction were of normal weight of $3.5 \pm 0.3 \mathrm{~g}$, and the mixed articular cartilage from ten mice was used for each cell extraction procedure. After fibronectin sorting, mice ACPCs were all observed to be short and shuttle-shaped, wider in the middle with slender ends, similar to the typical cell morphology of mesenchymal cells (Figure 1A). The $\mathrm{P} 1$ generation ACPCs were used for osteogenic, adipogenic, and chondrogenic induction to identify stem cell characteristics (Figure $1 A$ ). The results of flow cytometry counting showed that expression of the mesenchymal cell markers CD29 and CD73 were strongly positive with $89.2 \% \pm 1.53 \%$ and $81.1 \% \pm 0.84 \%$, respectively expressing these markers. Some cells were also positive for CD90 and CD105, with expression rates of $24.3 \% \pm 1.11 \%$ and $41.6 \% \pm 0.62 \%$, respectively. The possible specific surface marker of ACPCs, Notch-1, was weakly expressed in $12.0 \% \pm 1.05 \%$ of cells. The non-stem cell markers CD31, CD44, and CD45 were weakly positive or negative, with expression levels of $7.74 \% \pm 0.33 \%, 17.1 \% \pm 1.43 \%$, and $4.06 \% \pm 0.68 \%$, respectively (Figure $1 B$ ).

\section{Influence of bFGF on cell culture of ACPCs}

ACPCs were allocated equally to the three groups. The cell morphology became longer with increasing bFGF concentration [Figure $2 A$, (a)]. The $2 \mathrm{ng} / \mathrm{mL}$ bFGF group had the highest rate of colony formation, followed by the group without bFGF, while the least were formed by the $5 \mathrm{ng} / \mathrm{mL}$ bFGF group, and the differences were statistically significant [Figure $2 A$, (b,c); Figure $2 B$ ]. The $2 \mathrm{ng} / \mathrm{mL}$ bFGF group also had the highest number of cells, followed by the $5 \mathrm{ng} / \mathrm{mL}$ bFGF group, while the lowest number was found in the group without bFGF (Figure 2B). The fastest proliferation in the CCK-8 test was also found in the $2 \mathrm{ng} / \mathrm{mL}$ bFGF group, followed by the $5 \mathrm{ng} / \mathrm{mL}$ group, with the least in the group without bFGF, and again the differences were statistically significant (Figure 2B).

\section{Influence of bFGF on osteogenic induction of ACPCs}

ACPCs were allocated equally to the three groups, and after 3 weeks of osteogenic induction, all groups had alizarin redstained calcium nodules (Figure $3 A$ ). Images of the staining indicated that the number of calcium nodules decreased gradually with the increase in bFGF concentration (Figure 3A). Moreover, RT-PCR showed that the expression of osteocalcin, AKP, and RUNX2 also decreased gradually with increasing bFGF concentration. All differences were statistically significant (Figure 3B).

\section{Influence of bFGF on chondrogenic induction of ACPCs}

ACPCs were allocated equally to the three groups. All ACPCs cell pellets, regardless of whether they were cultured in chondrogenic induction medium or in ordinary medium, gradually increased in size with increasing bFGF concentration [Figure $4 A$, (a)]. In addition, the cell pellets in the induced group were larger than those in the noninduced group [Figure 4A, (a)]. However, in the induced group, HE staining indicated that in all three groups, the ACPCs pellet formed a cartilage lacuna structure, with the densest structure observed in the $2 \mathrm{ng} / \mathrm{mL}$ group [Figure $4 A$, (b)], and all three groups expressed high levels of COL-II 

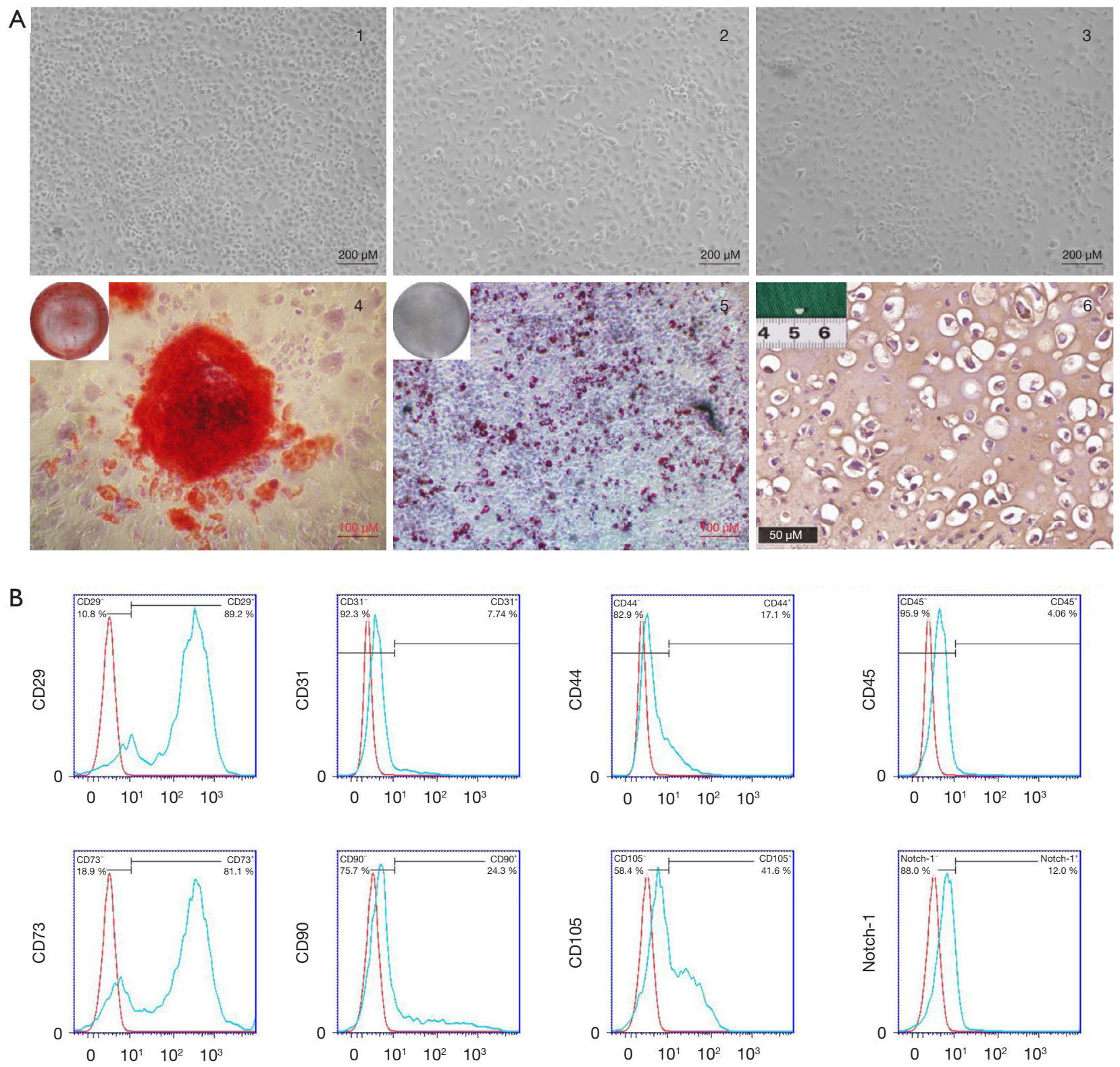

Figure 1 Isolation and identification of ACPCs. (A) Morphology of ACPCs after fibronectin sorting: (A-1) P0 generation ACPCs (100x), (A-2) P1 generation ACPCs (100x), (A-3) P2 generation ACPCs (100x), (A-4) Alizarin red S staining of ACPCs after osteogenic induction $(100 \times)$, gross view in top left corner, (A-5) Oil Red O staining of ACPCs after adipogenic induction (100x), gross view in top left corner, (A-6) type II collagen immunohistochemical staining of ACPCs after chondrogenic induction (200x), gross view in top left corner. (B) Flow cytometric analysis of $\mathrm{P} 0$ generation ACPCs. ACPCs, articular cartilage-derived progenitor cells.

[Figure $4 A$, (c)]. In the non-induced cell pellet cultures, the cell pellets in the $\alpha$-MEM group and the $2 \mathrm{ng} / \mathrm{mL}$ group had a more complete tissue structure after sectioning, and there were more homogeneous cartilage lacuna structures, while the cell pellets in the $5 \mathrm{ng} / \mathrm{mL}$ group had a looser structure with scattered cartilage lacunae within the tissue. COL-II was expressed in all three groups (Figure 4A).

There were significant differences in the expression of COMP, SOX9, Aggrecan, and COL-II between the simple $\alpha$-MEM culture group and the bFGF-treated groups (all $\mathrm{P}$ values were $<0.05$ ) (Figure $4 B$ ). However, between the $2 \mathrm{ng} / \mathrm{mL}$ and the $5 \mathrm{ng} / \mathrm{mL}$ bFGF groups, there was a 
A
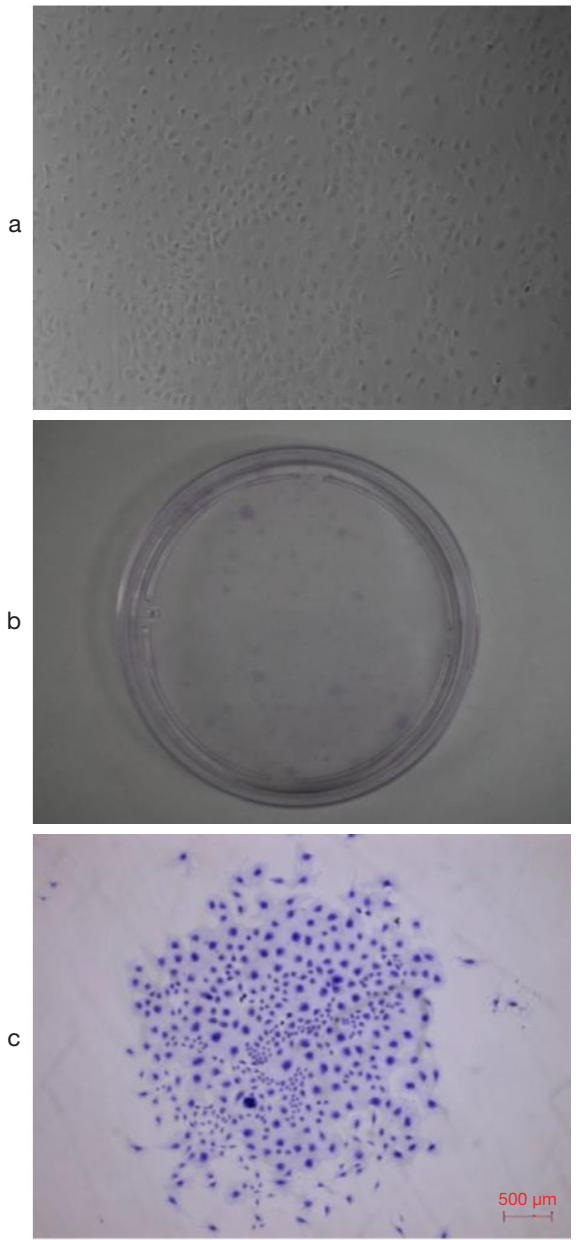

B

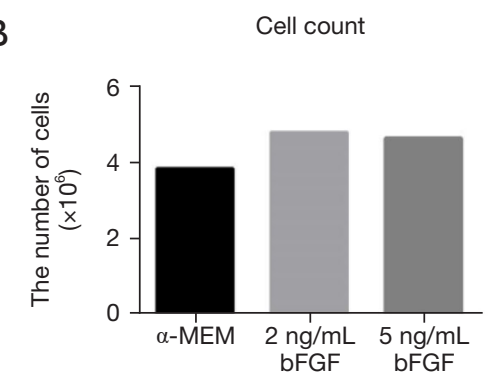

II
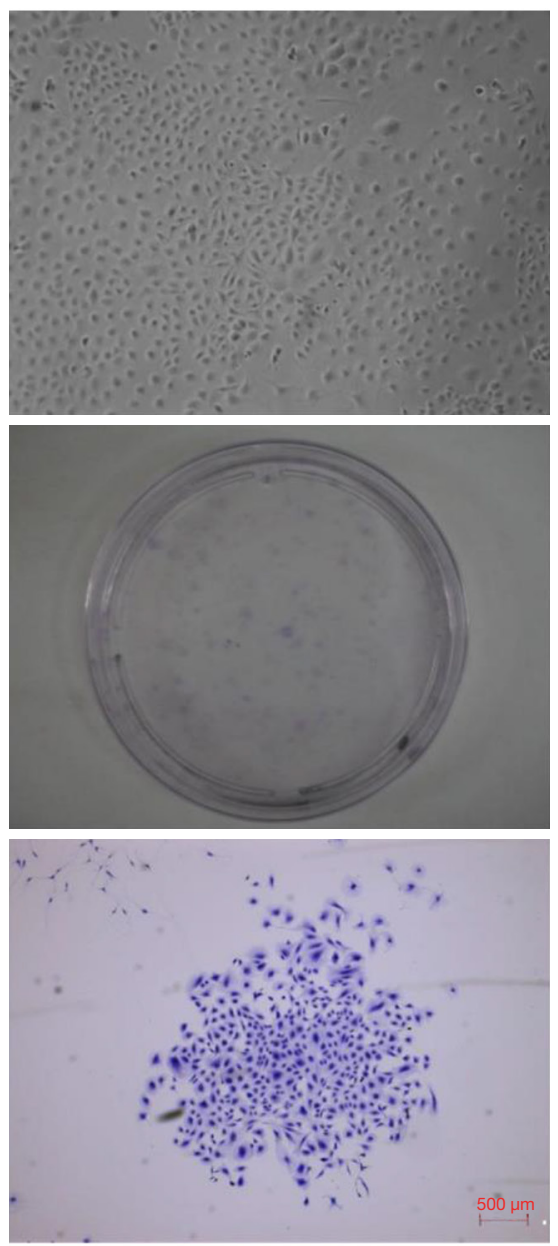

Colony formation assay

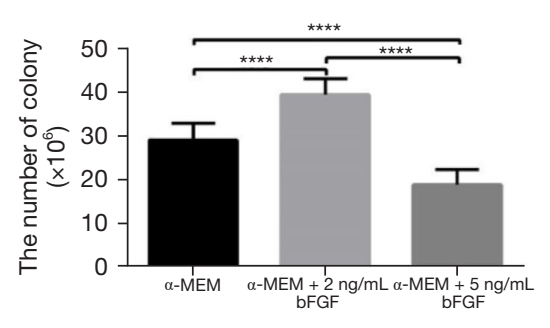

III
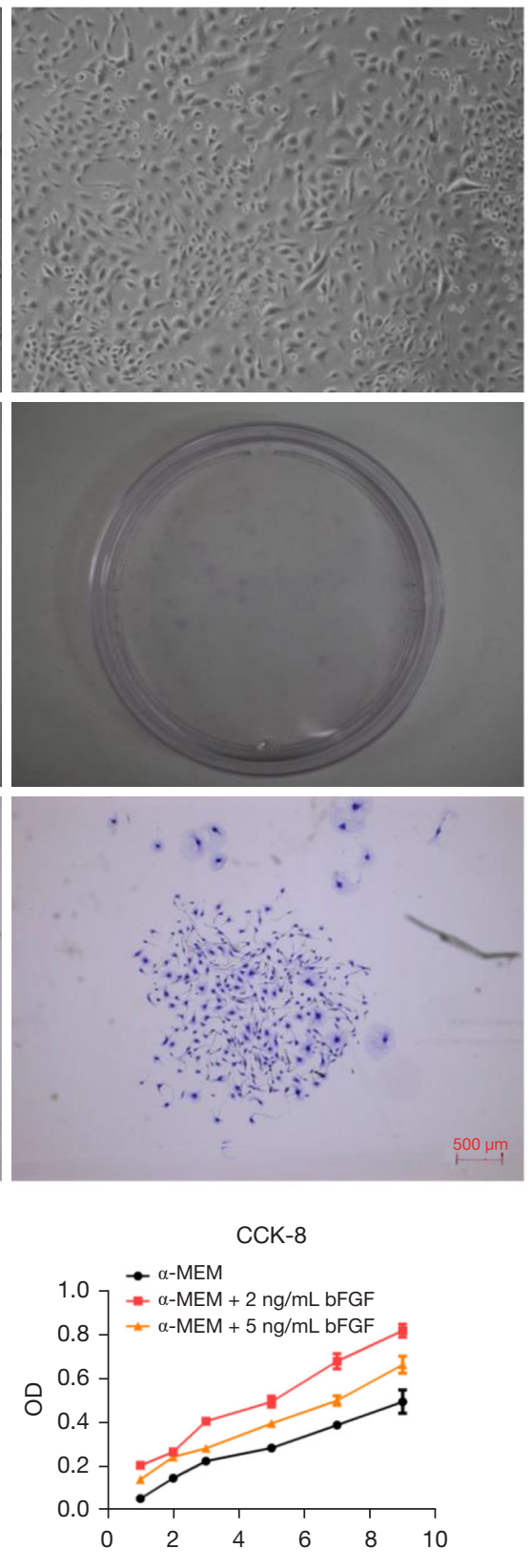

Figure 2 Influence of bFGF on cell culture of ACPCs. (A) Effect of bFGF on cell morphology and clone-forming ability of ACPCs. (I) $\alpha$-MEM medium group, (II) $\alpha$-MEM medium containing $2 \mathrm{ng} / \mathrm{mL}$ bFGF group, (III) $\alpha-M E M$ medium containing $5 \mathrm{ng} / \mathrm{mL}$ bFGF group. (a) Cell morphology $(100 \times)$, (b) crystal violet staining of clone-forming ability (gross view), (c) crystal violet staining of cell clone-forming morphology (40×). (B) Effect of bFGF on the proliferative capacity of P1 generation ACPCs $\left.{ }^{* * * *}, \mathrm{P}<0.0001\right)$. bFGF, basic fibroblast growth factor; ACPCs, articular cartilage-derived progenitor cells; $\alpha$-MEM, $\alpha$-minimum essential medium. 

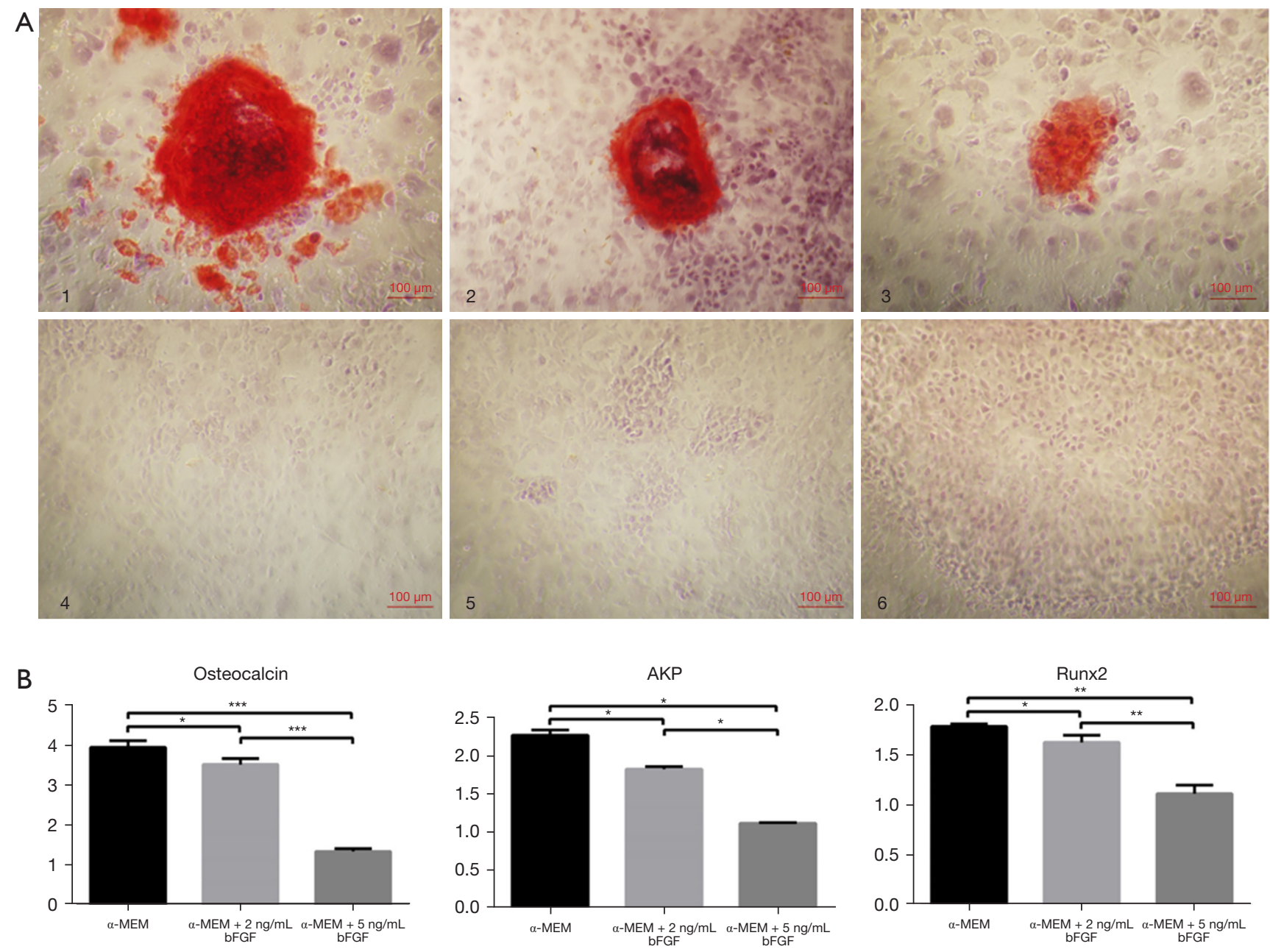

Figure 3 Effect of bFGF on the osteogenic capacity of ACPCs. (A) Alizarin red staining (100x): (A-1) $\alpha$-MEM medium osteogenic induction group, (A-2) $\alpha$-MEM medium containing $2 \mathrm{ng} / \mathrm{mL}$ bFGF osteogenic induction group, (A-3) $\alpha-M E M$ medium containing $5 \mathrm{ng} / \mathrm{mL}$ bFGF osteogenic induction group, (A-4) $\alpha$-MEM medium control group, (A-5) $\alpha$-MEM medium containing 2 ng/mL bFGF control group, (A-6) $\alpha$-MEM medium containing $5 \mathrm{ng} / \mathrm{mL}$ bFGF control group. (B) PCR result of ACPCs after osteogenic induction under different concentrations of bFGF culture $\left(*, \mathrm{P}<0.05\right.$; ${ }^{* *}, \mathrm{P}<0.01$; ***, $\left.\mathrm{P}<0.001\right)$. bFGF, basic fibroblast growth factor; ACPCs, articular cartilagederived progenitor cells; $\alpha$-MEM, $\alpha$-minimum essential medium; AKP, alkaline phosphatase; Runx2, runt-related transcription factor 2.

significant difference only in the expression of COL-II (P value $<0.05)$, while there was no significant difference in the expression of COMP, SOX9, or Aggrecan (Figure 4B).

\section{In vitro and in vivo cartilage construction of ACPCs on materials}

ACPCs of the $2 \mathrm{ng} / \mathrm{mL}$ bFGF group were incorporated into a gelatin/polycaprolactone (Gt/PCL) material and induced into cartilage in vitro for 4 weeks, after which a largely white, soft tissue was formed. HE staining showed a homogeneous cartilage lacuna structure with high expression of type II collagen, which was strongly positive for type $\mathrm{X}$ collagen and VEGF-A staining (Figure $5 A$ ). The complexes were implanted into the back of four healthy nude mice three times. During the in vivo culturing time, one nude mouse died. The tissue was removed at 8 weeks after implantation, and a white, hard tissue was formed. Further HE staining showed a more mature cartilaginous lacuna structure with similarly high expression of type II 
A

A

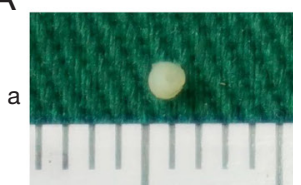

b
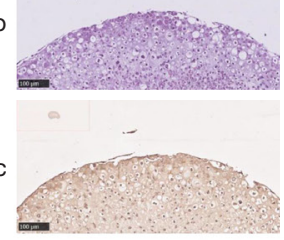

B
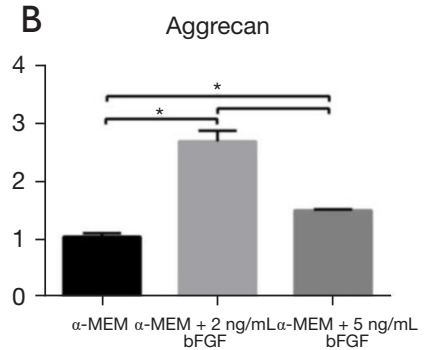

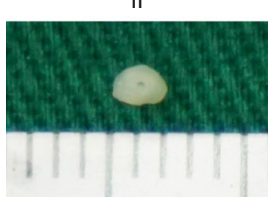

-

\begin{abstract}
II
\end{abstract}
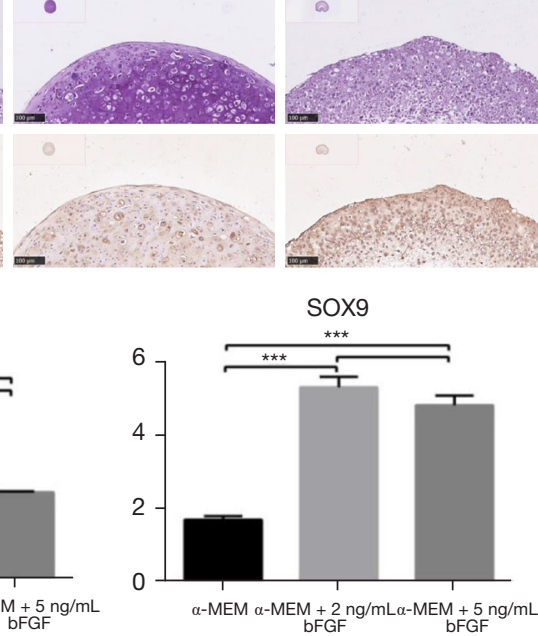

III

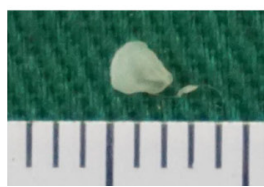

๑
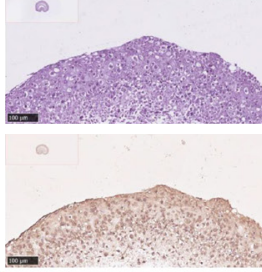

IV
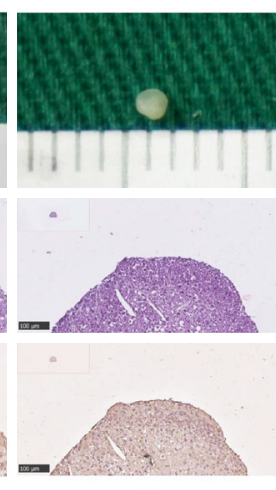

COL-II

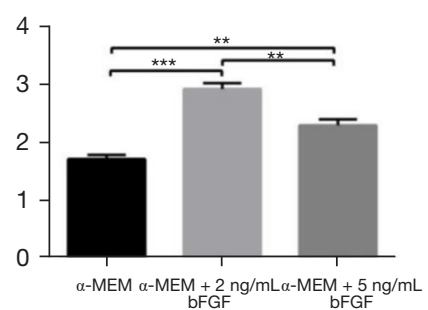

V
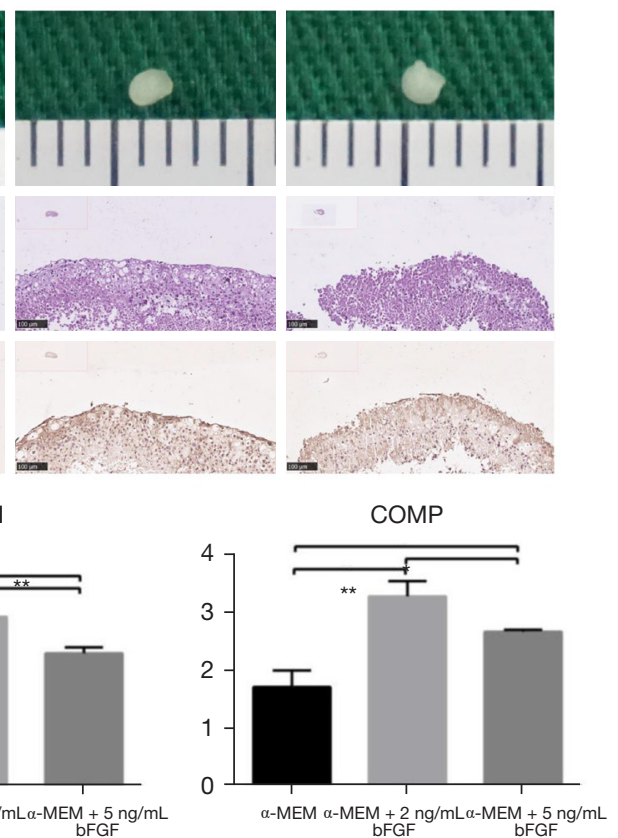

Figure 4 Effect of bFGF on the chondrogenic capacity of ACPCs. (A) Histologic result of ACPCs after chondrogenic induction under different concentrations of bFGF culture. (I) $\alpha$-MEM medium chondrogenic induction group, (II) $\alpha$-MEM medium containing 2 ng/mL bFGF chondrogenic induction group, (III) $\alpha$-MEM medium containing $5 \mathrm{ng} / \mathrm{mL}$ bFGF chondrogenic induction group, (IV) $\alpha-M E M$ medium control group, (V) $\alpha$-MEM medium containing $2 \mathrm{ng} / \mathrm{mL}$ bFGF control group, (VI) $\alpha$-MEM medium containing $5 \mathrm{ng} / \mathrm{mL}$ bFGF control group. (a) Gross view, (b) HE staining (100x), (c) type II collagen immunohistochemical staining (100x). (B) PCR result of ACPCs after chondrogenic induction under different concentrations of bFGF culture $\left({ }^{*}, \mathrm{P}<0.05 ;{ }^{* *}, \mathrm{P}<0.01 ;{ }^{* * *}, \mathrm{P}<0.001\right)$. bFGF, basic fibroblast growth factor; ACPCs, articular cartilage-derived progenitor cells; $\alpha$-MEM, $\alpha$-minimum essential medium; HE, hematoxylin and eosin; SOX-9, sex determining region Y-box 9; COL-II, type II collagen; COMP, cartilage oligomeric matrix protein.

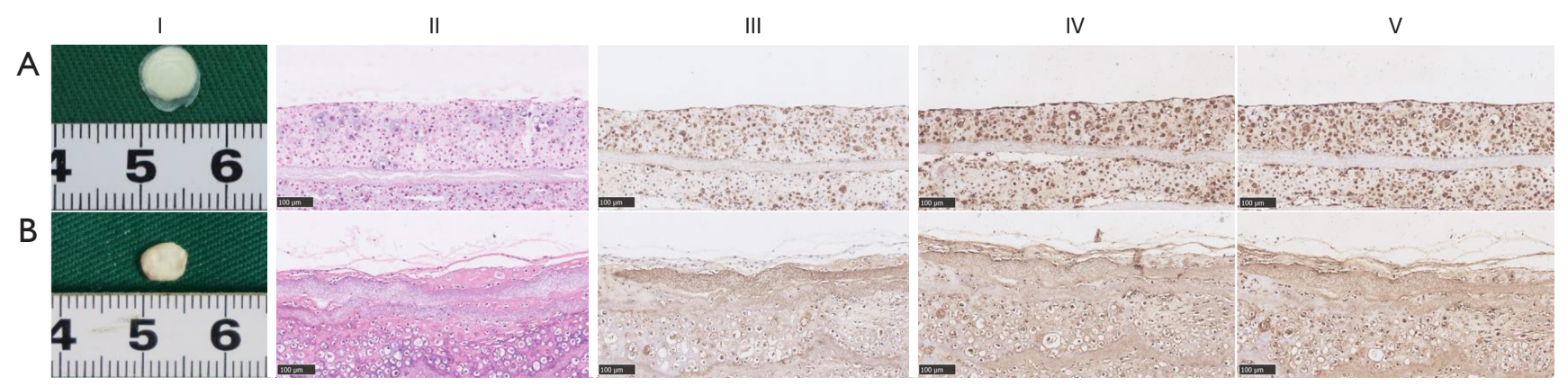

Figure 5 In vitro and in vivo cartilage construction of ACPCs on materials. (A) In vitro 4 weeks; (B) in vitro 4 weeks + in vivo 8 weeks. (I) Gross views, (II) HE staining (100x), (III) type II collagen immunohistochemical staining (100x), (IV) type X collagen immunohistochemical staining (100x), (V) VEGF-A immunohistochemical staining (100x). ACPCs, articular cartilage-derived progenitor cells; VEGF-A, vascular endothelial growth factor-A. 
collagen, type X collagen, and VEGF-A (Figure 5B).

\section{Discussion}

The weak regenerative capacity of cartilage means that the application of tissue engineering methods to repair cartilage defects has vast application prospects, and the problem of seed cell source is one of the most important aspects. The low chondrocyte content and limited proliferative capacity of cartilage make it difficult to repair larger cartilage defects. Mesenchymal stem cells, such as BMSCs, are abundant and readily available, and are the most commonly used seed cells for chondrogenic tissue engineering. However, cartilage tissue constructed from BMSCs is prone to chondrogenic hypertrophy and ossification after implantation (5-8). ACPCs, derived from articular cartilage, have mesenchymal properties and express cartilage-specific matrix proteins, making them a good source of seed cells $(16,21,22)$.

Since ACPCs lack specific surface markers, a widely used method for the isolation of ACPCs is the fibronectin adhesion method. The method mainly takes advantage of the fact that ACPCs express higher levels of integrin $\alpha 5$ and $\beta 1$ than chondrocytes (22-25), so that ACPCs can adhere more quickly to fibronectin-coated culture dishes. The cells obtained by this method were short and shuttle-shaped, which was consistent with the morphology of ACPCs reported in the literature (24). The three-orientation induction assay confirmed the osteogenic, chondrogenic, and adipogenic ability of the sorted cells. Flow cytometric analysis showed that the sorted cells positively expressed CD29, CD73, and CD105, which are the minimum criteria for mesenchymal cell identification, while the expression of surface markers associated with the hematopoietic lineage were negative. All these results indicated that the cells obtained in this study were ACPCs.

bFGF occurs within the structure of extracellular matrix of hyaline cartilage, This factor promotes the proliferation of chondrocytes in vivo. It was also shown that bFGF (with FGF-4 and FGF-8) plays a role in the process of anabolic pathways activation which leads to decrease of aggrecanase effect after cartilage load. It prevents cartilage against damage and osteoarthritis development (26). There are other factors promote chondrocyte proliferation, such as TGF- $\beta 1$, IGF-1, and PDGF $(27,28)$. bFGF has advantage of regulating the proliferation and differentiation balance that is needed for cartilage repair (29), which is commonly used for the in vitro expansion of both chondrocytes and BMSCs, and promotes the proliferation of chondrocytes and mesenchymal cells, as well as the chondrogenic differentiation of BMSCs. The commonly used concentration for MSC culture is $5 \mathrm{ng} / \mathrm{mL}(20,30)$, above $5.72 \mathrm{ng} / \mathrm{mL}$ bFGF will slow down proliferation of chondrocyte (28). Considering the effect of bFGF depending on concentration, then 2 and $5 \mathrm{ng} / \mathrm{mL}$ bFGF were added to medium. The results in the present study suggest that the cell morphology of mouse ACPCs gradually changed from a short shuttle shape to a long and slender shuttle shape with increasing bFGF concentration, until at a concentration of $5 \mathrm{ng} / \mathrm{mL}$ the cell morphology was closer to that of BMSCs. In cell culture, elongated pseudopod-like structures could be seen at both ends of the cells, and this phenomenon was more obvious in the colony forming experiments.

However, the results of the present study showed that the number of single cell clonal clusters in the $5 \mathrm{ng} / \mathrm{mL}$ bFGF group was lower than in the $2 \mathrm{ng} / \mathrm{mL}$ bFGF group or in the group without bFGF. The CCK- 8 assay also showed that the addition of $2 \mathrm{ng} / \mathrm{mL}$ bFGF to the medium resulted in the highest $\mathrm{OD}$ values at all time points. This phenomenon suggests $5 \mathrm{ng} / \mathrm{mL}$ bFGF may be an excessively high concentration in mouse ACPCs and may not promote cell proliferation, but instead, inhibits the normal growth of ACPCs, ultimately leading to cell aging and apoptosis. Effect of bFGF on cell apoptosis will be tested in the future work.

Different concentrations of bFGF can affect the osteogenic ability of mice ACPCs in culture. On the one hand, the results of Alizarin red S staining showed that the osteogenic differentiation ability of mice ACPCs decreased with increasing bFGF concentration. On the other hand, the results of RT-PCR suggest that the expression of osteogenic genes decreased as the concentration of bFGF increased. Combining the results of Alizarin red S staining and the expression of osteogenesis-related genes, it could be assumed bFGF inhibits the osteogenic differentiation of mice ACPCs, and that this effect is positively correlated with the bFGF concentration.

Incubation with different concentrations of bFGF can affect the chondrogenic ability of mice ACPCs. Gross observation of the cell pellets showed that ACPCs in the $5 \mathrm{ng} / \mathrm{mL}$ bFGF group formed the largest cell pellets under chondrogenic conditions. However, HE staining showed that their internal structure was looser and would lead to instability of the cartilage tissue. Immunohistochemical staining of type II collagen indicated that the addition of bFGF to mouse ACPCs during cell expansion increased the number of positive areas for cell clumps in both the induction and control groups. RT-PCR results suggested 
that the cell pellet constructed by cells of the $2 \mathrm{ng} / \mathrm{mL}$ bFGF group had the highest expression of chondrogenesisrelated genes. This suggested that $2 \mathrm{ng} / \mathrm{mL}$ bFGF was the optimal concentration to promote the chondrogenic ability of ACPCs.

As bFGF could promote chondrocyte healing process in 3-D in vitro models for joint wound healing (31). After optimize the cell culture condition, ACPCs were constructed according to the "sandwich" model. In vitro cartilage was induced to form a white soft tissue, and the histology showed a homogeneous cartilage lacuna structure. However, it still expressed type $\mathrm{X}$ collagen, suggesting a tendency to differentiate into hypertrophic cartilage. Moreover, VEGF-A staining was also positive, suggesting that it may attract vascular endothelial cells, which may cause endochondral ossification. Eight weeks after in vivo implantation in nude mice, the tissues became rigid, remained white in appearance, and the structure of the cartilage lacunae became more mature, with a high expression of cartilage-specific matrix type II collagen. At the same time, homogenous expression of type $\mathrm{X}$ collagen and VEGF-A could be seen. These results suggest that ACPCs can form homogenous cartilage lacuna structures in vitro and in vivo after optimization of culture conditions. However, long-term in vivo results are still lacking, and will be investigated in subsequent experiments.

The results of this experiment using mice ACPCs suggests we could apply a similar system to human ACPCs, with the potential to develop a practical method to repair cartilage defects in humans.

\section{Conclusions}

Culture in $\alpha$-MEM containing $2 \mathrm{ng} / \mathrm{mL} \mathrm{bFGF}$ is the most suitable cell expansion protocol, and can effectively promote the expansion of ACPCs, while maintaining their chondrogenic potential.

\section{Acknowledgments}

Funding: The present study was supported by the National Natural Science Foundation of China (grant Nos. 82072442, 81772358, 82001978, 81702048).

\section{Footnote}

Reporting Checklist: The authors have completed the ARRIVE reporting checklist. Available at https://atm. amegroups.com/article/view/10.21037/atm-21-5604/rc

Data Sharing Statement: Available at https://atm.amegroups. com/article/view/10.21037/atm-21-5604/dss

Conflicts of Interest: All authors have completed the ICMJE uniform disclosure form (available at https://atm. amegroups.com/article/view/10.21037/atm-21-5604/coif). The authors have no conflicts of interest to declare.

Ethical Statement: The authors are accountable for all aspects of the work in ensuring that questions related to the accuracy or integrity of any part of the work are appropriately investigated and resolved. All animal experimental procedures were approved by the Animal Care and Experiment Committee of Soochow University (application numbers 201811A525, 201810A271), in compliance with institutional guidelines for the care and use of animals.

Open Access Statement: This is an Open Access article distributed in accordance with the Creative Commons Attribution-NonCommercial-NoDerivs 4.0 International License (CC BY-NC-ND 4.0), which permits the noncommercial replication and distribution of the article with the strict proviso that no changes or edits are made and the original work is properly cited (including links to both the formal publication through the relevant DOI and the license). See: https://creativecommons.org/licenses/by-nc-nd/4.0/.

\section{References}

1. Crisan M, Yap S, Casteilla L, et al. A perivascular origin for mesenchymal stem cells in multiple human organs. Cell Stem Cell 2008;3:301-13.

2. Park YB, Ha CW, Rhim JH, et al. Stem Cell Therapy for Articular Cartilage Repair: Review of the Entity of Cell Populations Used and the Result of the Clinical Application of Each Entity. Am J Sports Med 2018;46:2540-52.

3. Wang Z, Li K, Sun H, et al. Icariin promotes stable chondrogenic differentiation of bone marrow mesenchymal stem cells in self assembling peptide nanofiber hydrogel scaffolds. Mol Med Rep 2018;17:8237-43.

4. Williams R, Khan IM, Richardson K, et al. Identification and clonal characterisation of a progenitor cell subpopulation in normal human articular cartilage. PLoS One 2010;5:e13246. 
5. Bernstein P, Sticht C, Jacobi A, et al. Expression pattern differences between osteoarthritic chondrocytes and mesenchymal stem cells during chondrogenic differentiation. Osteoarthritis Cartilage 2010;18:1596-607.

6. Mareddy S, Crawford R, Brooke G, et al. Clonal isolation and characterization of bone marrow stromal cells from patients with osteoarthritis. Tissue Eng 2007;13:819-29.

7. Pelttari K, Winter A, Steck E, et al. Premature induction of hypertrophy during in vitro chondrogenesis of human mesenchymal stem cells correlates with calcification and vascular invasion after ectopic transplantation in SCID mice. Arthritis Rheum 2006;54:3254-66.

8. Karlsson C, Stenhamre H, Sandstedt J, et al. Neither Notch1 expression nor cellular size correlate with mesenchymal stem cell properties of adult articular chondrocytes. Cells Tissues Organs 2008;187:275-85.

9. Grogan SP, Miyaki S, Asahara H, et al. Mesenchymal progenitor cell markers in human articular cartilage: normal distribution and changes in osteoarthritis. Arthritis Res Ther 2009;11:R85.

10. Hayes AJ, Tudor D, Nowell MA, et al. Chondroitin sulfate sulfation motifs as putative biomarkers for isolation of articular cartilage progenitor cells. J Histochem Cytochem 2008;56:125-38.

11. Hattori S, Oxford C, Reddi AH. Identification of superficial zone articular chondrocyte stem/progenitor cells. Biochem Biophys Res Commun 2007;358:99-103.

12. Kennon JC, Awad ME, Chutkan N, et al. Current insights on use of growth factors as therapy for Intervertebral Disc Degeneration. Biomol Concepts 2018;9:43-52.

13. Suzuki F. Cartilage-derived growth factor and antitumor factor: past, present, and future studies. Biochem Biophys Res Commun 1999;259:1-7.

14. Vincent T, Saklatvala J. Basic fibroblast growth factor: an extracellular mechanotransducer in articular cartilage? Biochem Soc Trans 2006;34:456-7.

15. Shu C, Smith SM, Little CB, et al. Use of FGF-2 and FGF-18 to direct bone marrow stromal stem cells to chondrogenic and osteogenic lineages. Future Sci OA 2016;2:FSO142.

16. Stewart K, Pabbruwe M, Dickinson S, et al. The effect of growth factor treatment on meniscal chondrocyte proliferation and differentiation on polyglycolic acid scaffolds. Tissue Eng 2007;13:271-80.

17. Arévalo-Silva CA, Cao Y, Weng Y, et al. The effect of fibroblast growth factor and transforming growth factorbeta on porcine chondrocytes and tissue-engineered autologous elastic cartilage. Tissue Eng 2001;7:81-8.

18. Tsutsumi S, Shimazu A, Miyazaki K, et al. Retention of multilineage differentiation potential of mesenchymal cells during proliferation in response to FGF. Biochem Biophys Res Commun 2001;288:413-9.

19. Correa D, Somoza RA, Lin P, et al. Sequential exposure to fibroblast growth factors (FGF) 2, 9 and 18 enhances hMSC chondrogenic differentiation. Osteoarthritis Cartilage 2015;23:443-53.

20. Zhou X, Tao Y, Wang J, et al. Roles of FGF-2 and TGFbeta/FGF-2 on differentiation of human mesenchymal stem cells towards nucleus pulposus-like phenotype. Growth Factors 2015;33:23-30.

21. McCarthy HE, Bara JJ, Brakspear K, et al. The comparison of equine articular cartilage progenitor cells and bone marrow-derived stromal cells as potential cell sources for cartilage repair in the horse. Vet J 2012;192:345-51.

22. Marcus P, De Bari C, Dell'accio F, et al. Articular Chondroprogenitor Cells Maintain Chondrogenic Potential but Fail to Form a Functional Matrix When Implanted Into Muscles of SCID Mice. Cartilage 2014;5:231-40.

23. Martin JM, Smith M, Al-Rubeai M. Cryopreservation and in vitro expansion of chondroprogenitor cells isolated from the superficial zone of articular cartilage. Biotechnol Prog 2005;21:168-77.

24. Melero-Martin JM, Dowling MA, Smith M, et al. Optimal in-vitro expansion of chondroprogenitor cells in monolayer culture. Biotechnol Bioeng 2006;93:519-33.

25. Dowthwaite GP, Bishop JC, Redman SN, et al. The surface of articular cartilage contains a progenitor cell population. J Cell Sci 2004;117:889-97.

26. Ge Z, Hu Y, Heng BC, et al. Osteoarthritis and therapy. Arthritis Rheum 2006;55:493-500.

27. Brandl A, Angele P, Roll C, et al. Influence of the growth factors PDGF-BB, TGF-beta1 and bFGF on the replicative aging of human articular chondrocytes during in vitro expansion. J Orthop Res 2010;28:354-60.

28. Li Y, Qin J, Lin B, et al. The effects of insulin-like growth factor-1 and basic fibroblast growth factor on the proliferation of chondrocytes embedded in the collagen gel using an integrated microfluidic device. Tissue Eng Part C Methods 2010;16:1267-75.

29. Schmal H, Zwingmann J, Fehrenbach M, et al. bFGF influences human articular chondrocyte differentiation. Cytotherapy 2007;9:184-93.

30. Ehlicke F, Freimark D, Heil B, et al. Intervertebral disc regeneration: influence of growth factors on differentiation 
of human mesenchymal stem cells (hMSC). Int J Artif Organs 2010;33:244-52.

31. Tsai YH, Chen CW, Lai WF, et al. Phenotypic changes in proliferation, differentiation, and migration of

Cite this article as: Shen X, Zhu T, Xue J, Zhang Y, Lu Y, Yang H, Yu Z, Zhu Y, Zhu X. Influence of bFGF on in vitro expansion and chondrogenic construction of articular cartilagederived progenitor cells. Ann Transl Med 2022;10(2):36. doi: 10.21037/atm-21-5604 chondrocytes: 3D in vitro models for joint wound healing. J Biomed Mater Res A 2010;92:1115-22.

(English Language Editor: B. Draper) 